\title{
Localization of Choline Acetyltransferase within Identified Motoneurons of the Nematode Ascaris ${ }^{1}$
}

\author{
CARL D. JOHNSON ${ }^{2}$ AND ANTONY O. W. STRETTON \\ Department of Zoology, University of Wisconsin-Madison, Madison, Wisconsin 53706
}

\begin{abstract}
Choline acetyltransferase (CAT) activity has been measured in the nematode Ascaris lumbricoides. Strips of hypodermal tissue which contained branches of single identified motoneurons (Stretton, A. O. W., R. M. Fishpool, E. Southgate, J. E. Donmoyer, J. P. Walrond, and I. S. Kass (1978) Proc. Natl. Acad. Sci. U. S. A. 75: 3493-3497) as well as control strips containing no neural tissue were assayed. In strips of hypodermis which contained branches of excitatory motoneurons (classes DE1, DE2, and DE3), CAT activity was elevated 5 to 10 times compared to control levels. Branches of inhibitory motoneurons (classes $\mathrm{DI}$ and $\mathrm{VI}$ ) did not add to the level of CAT observed in the controls. These data provide additional support for the suggestion (e.g., del Castillo, J., W. C. deMello, and T. Morales (1963) Experientia 20: 141) that acetylcholine is an excitatory neurotransmitter at nematode neuromuscular junctions. The function of the low level of CAT observed throughout the hypodermis is unknown.
\end{abstract}

As part of investigations into the cellular basis of behavior in nematodes, we are studying the localization of enzymes and receptors relaled to putative neurotransmitter substances in both neural and non-neural tissues in the large nematode Ascaris lumbricoides. Nematodes are excellent organisms in which to study localization of these molecules because they contain only a limited number of cells arranged in comparatively simple tissues. We have chosen to analyze localization in Ascaris because it is a large nematode with large nerve cells, some of which can be dissected for single-cell analysis. Most other nematodes are too small to allow the dissection of single nerve cells. However, since the anatomy of the nervous system of other nematodes is very similiar to that of Ascaris, it is reasonable to assume that this similarity will apply at the level of localization of enzymes and receptors and that cells containing a particular molecule in Ascaris will contain it in analogous cells in other nematodes as well.

In this paper we report the localization of choline acetyltransferase (CAT) (acetyl-CoA-choline acetyltransferase, EC 2.3.1.6), the enzyme which synthesizes acetycholine (ACh) within the motoneurons which innervate the body wall muscle cells of Ascaris. The anatomy of these motoneurons has been determined in detail by reconstruc-

Received July 2, 1984; Revised January 15, 1985

Accepted January 16, 1985

\footnotetext{
${ }^{1}$ This work was supported by United States Public Health Service Grants Al 15429, Al 15890, and Al 20355, a Muscular Dystrophy Association of America postdoctoral fellowship to C. D. J., and a Sloan Fellowship to A. O. W. S. We thank A. Aaroen, A. Chambers, C. Hughes, D. Chandler, and L. Vanderploeg for their help in preparing the manuscript.

${ }^{2}$ To whom correspondence should be addressed.
}

tion of serial sections (Stretton et al., 1978). Based upon shape alone, they have been grouped into seven classes. The cell bodies of members of the seven classes are arranged in a repeating pattern in the ventral nerve cord. Each repeating unit contains 11 motoneurons; three classes are represented once in each repeating unit, and the other four classes are represented twice $[3+(2 \times 4)=11]$. Each motoneuron has a ventral process which projects a characteristic direction and distance in the ventral nerve cord. Neurons of five classes also have a process in the dorsal nerve cord. For each of these five classes, the ventral and dorsal processes are connected by a process which traverses the circumference of the animal embedded in the thin layer of hypodermal tissue which underlies the muscle cells (see Fig. 1). These branches have been referred to as commissures since they were discovered in the late 1800s (Hesse, 1892). Because in other animals the term commissure has often been used to refer to bundles of neuron fibers, it is important to emphasize that the commissures referred to in this paper are single branches of identified motoneurons (Stretton et al., 1978).

By taking advantage of the commissures, previous studies from this laboratory (for review, see Johnson and Stretton, 1980) have investigated the physiological properties of these motoneurons and have determined whether they make excitatory or inhibitory synapses (Stretton et al., 1978; Walrond et al., 1985). Three of the classes are excitatory motoneurons; two are inhibitory. The present study indicates that CAT activity is selectively elevated in strips of hypodermis containing the commissures of all members of the three classes of excitatory motoneurons. In contrast, CAT was not elevated when the strips contained commissures of the two classes of inhibitory motoneurons. This result adds a striking biochemical correlate to the anatomical and physiological characterization of motoneurons in Ascaris and provides strong, indirect evidence that ACh functions as a neurotransmitter of the Ascaris excitatory motoneurons. We predict that analogous motoneurons in other nematode species will also be cholinergic

The results also indicate a second, non-neural localization of CAT. Low levels of CAT activity are found throughout body hypodermis; a much higher level of CAT exists in the hypodermis of the first 1 $\mathrm{mm}$ of the worm (C. D. Johnson and A. O. W. Stretton, manuscript in preparation). This resull was unexpected, and the function of $\mathrm{ACh}$ synthesized in the hypodermis is currently under investigation.

Some of these results have appeared previously in abstract form (Johnson and Stretton, 1977)

\section{Materials and Methods}

Ascaris !umbricoides var. suum was obtained from the small intestines of pigs at a local slaughter house. They were transported and maintained at $37^{\circ} \mathrm{C}$ in $1.5 \mathrm{~mm} \mathrm{NaOH}, 150 \mathrm{~mm} \mathrm{NaCl}$ or in phosphate-buffered saline (PBS; $50 \mathrm{~mm}$ sodium phosphate, $\mathrm{pH} 7.4,150 \mathrm{~mm} \mathrm{NaCl}$ ). Animals used in these experiments had been maintained less than 2 days in vitro. In preparation for dissection of commissures, large $(\sim 30 \mathrm{~cm})$ adult females were injected with 0.5 to $1.0 \mathrm{mg}$ of collagenase (Worthington type CLS IIt or IV) or pronase (Calbiochem) in $0.5 \mathrm{ml}$ of Ascaris saline solution. These proteases digest the connections between muscle cells and the hypodermal layer in which the 
nervous system is embedded. Hypodermis remains attached to the cuticle After cutting along one lateral line (usually the left), the hypodermis-cuticle was pinned out in a Sylgard-lined dish, washed free of dissociated tissues with PBS, and viewed in a dissecting microscope using darkfield illumination. The commissures appeared as 10 . to $20-\mu \mathrm{m}$ wide, clear fibers embedded in a grainy background (Fig. 1)

Strips of tissue containing single commissures were obtained by cutting through the hypodermis on both sides of the neuron process with an electrolytically sharpened tungsten needle. The hypodermis was also cut longitudinally next to the nerve cord and the lateral line, and the resultant strip of hypodermal tissue was gently pulled away from the cuticle with fine forceps.

\section{CAT assay}

Two procedures were utilized to assay CAT activity. The first procedure was adopted after pilot studies which tested a variety of assay techniques since it yielded differential localization of CAT in neurons and was relatively free from interference. The second procedure is more sensitive, but requires additional steps to reduce interference (see below). Both procedures were carried out in small U-shaped plastic wells (Linbro no. 76-013-05, 96-well plate).

Procedure 1. The hypodermal strips were transferred to $100 \mu \mathrm{l}$ of $\mathrm{H}_{2} \mathrm{O}$, frozen at $-20^{\circ} \mathrm{C}$ for $1 \mathrm{hr}$, and then transferred to fresh wells and covered with $5 \mu$ l of CAT assay mixture buffered with HEPES at $\mathrm{pH} 7.0$.

Procedure 2. Strips were transferred to wells containing $5 \mu \mathrm{l}$ of $\mathrm{H}_{2} \mathrm{O}$, followed by addition of $5 \mu \mathrm{l}$ of twice concentrated CAT assay mixture buffered with Tricine at $\mathrm{pH} 8.1$. The CAT assay mixture consisted of $50 \mathrm{~mm}$ HEPES pH 7.0, or 20 mm Tricine, pH 8.1, 1 mm acetyl-CoA (Sigma no. A2897), 0.5 $\mathrm{mm}$ neostigmine bromide (Sigma), 1 mm EDTA, $0.2 \mathrm{~mm}$ sodium azide, $1 \mathrm{mg} /$ $\mathrm{ml}$ of cytochrome $\mathrm{c}$ (Sigma no. 7752 ) and 0.05 to $0.2 \mu \mathrm{Ci}$ of [methyl- ${ }^{3} \mathrm{H}$ ] choline (New England Nuclear NET-190, 50 to $80 \mathrm{Ci} / \mathrm{mmol}$ ). $\left[{ }^{3} \mathrm{H}\right]$ Choline was routinely purified (in 50 - to $100-\mu \mathrm{Ci}$ lots) by high voltage paper electrophoresis (Hildebrand et al., 1971) in order to reduce the blank (from 2 to $3 \%$ of tota extractable counts per minute to as low as $0.2 \%$ ). The incubation was carried out in a moist chamber at 10 to $12^{\circ} \mathrm{C}$ to maximize enzyme stability, and for prolonged time periods ( 30 to $50 \mathrm{hr}$ ) to generate detectable amounts of $\left[{ }^{3} \mathrm{H}\right]$ ACh.

The incubation was terminated with the addition of $75 \mu \mathrm{l}$ of $100 \mathrm{~mm}$ Tris $\mathrm{HCl}$ (pH 8.2), $20 \mathrm{mM} \mathrm{MgCl}_{2}, 10 \mathrm{mM}$ ATP containing $\sim 0.04$ unit of choline kinase (prepared from Sigma Type YBB yeast-see Rand and Johnson, 1981). This mixture was transferred to a 1-dram glass vial, and the well was washed out with an additional $75 \mu$ l of Tris-Mg-ATP and incubated for 10 $\mathrm{min}$. For procedure 2, $25 \mu \mathrm{l}$ of $10 \mathrm{~mm}$ sodium borohydride (freshly prepared in $1 \mathrm{~mm} \mathrm{NaOH}$ ) and an additional aliquot of choline kinase were added to the vial and incubated for an additional $10 \mathrm{~min}$ at room temperature. Finally, $200 \mu \mathrm{l}$ of $\mathrm{H}_{2} \mathrm{O}, 25 \mu \mathrm{l}$ of $100 \mathrm{mg} / \mathrm{ml}$ sodium tetraphenylboron (Sigma) in $n$. butanol, and $4 \mathrm{ml}$, of toluene:10\% $n$-butanol scintillation fluid were added. The vial was then capped, shaken, and counted. In the two-phase system formed, acetyl- $\left[{ }^{3} \mathrm{H}\right]$ choline is efficiently extracted into the scintillation fluid where it is counted. Unreacted substrate $\left[{ }^{3} \mathrm{H}\right]$ choline, now converted by the
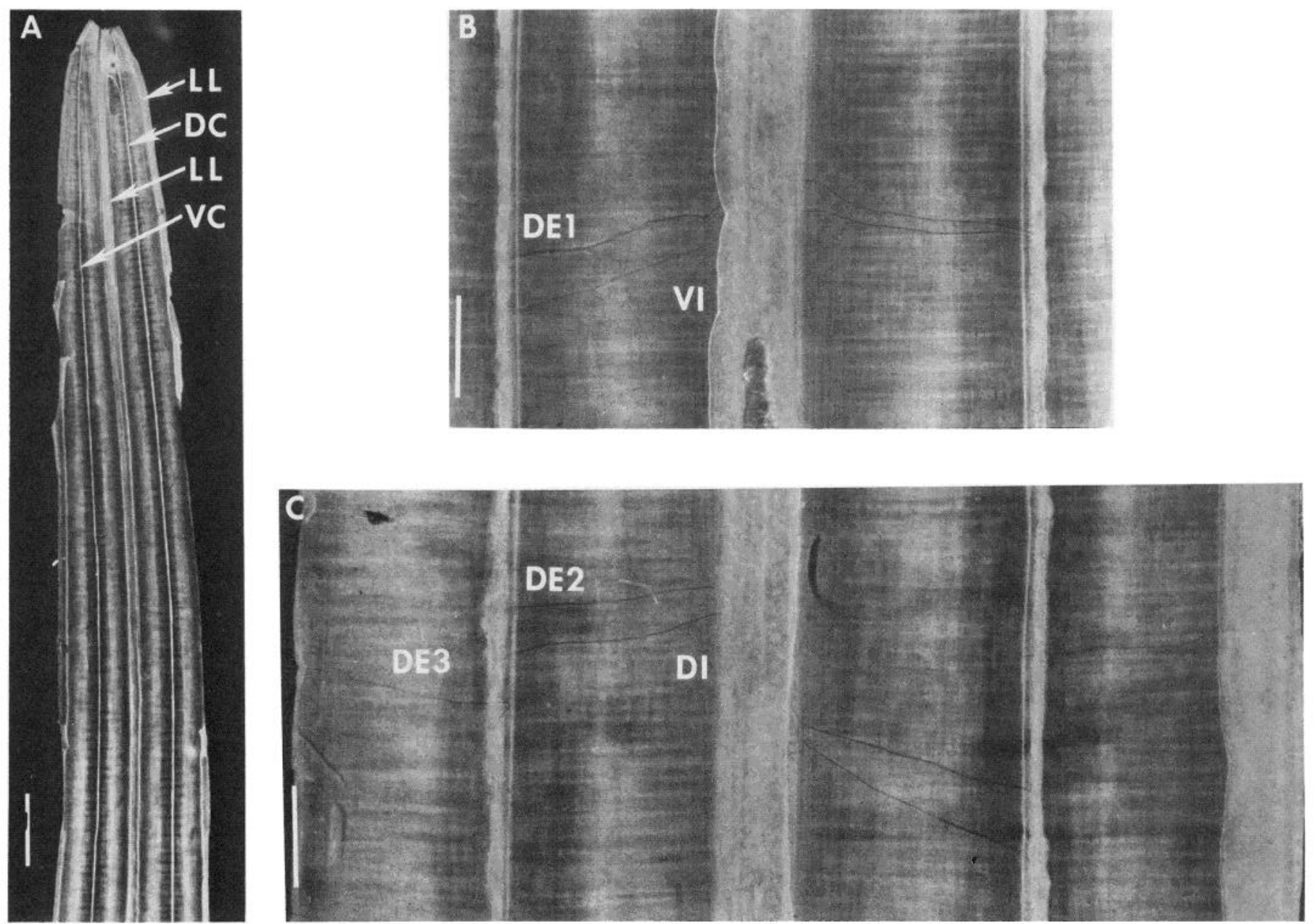

Figure 1. Photographs of the preparation. A female Ascaris, prepared for dissecting commissures as described under "Materials and Methods," was placed between two glass microscope slides and photographed with darkfield optics. A. Photograph of the anterior half of the preparation. The hypodermiscuticle has been cut along the left lateral line. The right lateral line is visible in the center of the preparation. Ventral and dorsal nerve cords can be seen as thin white lines. The tip of the head is at the top of the photograph. $B$. Photograph of a DE1/VI commissure pair. On the ventral (Heft) side of the lateral line, the DE1 commissure is anterior to and distinctly thicker than the VI commissure. C. Photograph of a DE2/DI/DE3 commissure group. The right-handed pair of commissures includes a DE2 and a DI. Near the ventral cord (left), the DE2 is anterior to and thicker than the DI. The DE3 commissure is to the left. Scale bars: $A, 1 \mathrm{~cm} ; B$ and $C, 1 \mathrm{~mm}$. 
action of choline kinase to phosphoryl-[ $\left.{ }^{3} \mathrm{H}\right]$ choline remains in the aqueous phase and is not counted (Rand and Johnson, 1981). Borohydride treatment eliminates the interference of choline dehydrogenase by converting the product of this enzyme $\left(\left[{ }^{3} \mathrm{H} \mid\right.\right.$ betaine aldehyde) back to $\left[{ }^{3} \mathrm{H}\right]$ choline which is subsequently phosphorylated during the termination reaction.

Each set of assays included several blanks (no tissue) as well as several measurements of total extractable counts per minute (estimated by eliminating the choline kinase in the termination procedure). CAT activity is expressed as fractional conversion of $\left[{ }^{3} \mathrm{H}\right]$ choline to $\left[{ }^{3} \mathrm{H}\right] \mathrm{ACh}$ converted to $V_{\max } / K_{\mathrm{m}}$ units (Rand and Johnson, 1981). For the fractional conversion

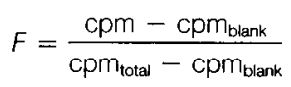

we use a logarithmic transformation which corrects for substrate depletion assuming that substrate concentration is well below the $K_{m}$ : the corrected fractional conversion, $F_{c}=-I n(1-F)$. Finally, $V_{\max } / K_{m}=F_{c} \times v / t$ where $v$ is the assay volume and $t$ is the assay time. $V_{\max } / K_{\mathrm{m}}$ is reported in units of

$$
\frac{\mu \mathrm{mol}}{\mathrm{min}} / \frac{\mu \mathrm{mol}}{\text { liter }}=\frac{\text { liter }}{\min } \text { per commissure }
$$

\section{Results}

Each commissure is known from anatomical studies (Stretton et al., 1978) to contain the process of a single identified motoneuron. Five of the seven classes (Fig. 2) of motoneurons (DE1, DE2, DE3, $\mathrm{Dl}$, and $\mathrm{VI})$ have a commissure. Most of them are arranged in two types of groups: $\mathrm{DE} 1$ and $\mathrm{VI}$ commissures are paired in a "two to the right," or $2 \mathrm{R}$, grouping (Fig. $1 B$ ), and the commissures of DE2, $\mathrm{DI}$, and DE3 neurons occur in a "two to the right, one to the left," or 2R1L, grouping (Fig. 1C)

Position alone is sufficient to identify the commissures of class DE3 motoneurons - they are the single left-handed commissures. The right-handed commissures of the remaining four classes of neurons are distinguished using the following criteria (Fig. 3). Within the pairs of commissures, those of the excitatory neurons (DE1 or DE2) are usually anterior to those of the inhibitory neurons (VI or DI) and can be seen to connect directly to their cell bodies in the ventral nerve cord. The cell bodies of the inhibitory motoneurons are posterior to their commissures in the ventral nerve cord. In addition, excitatory commissures often appear thicker than inhibitory commissures.

In general there are two 2R groups for each $2 \mathrm{R} 1 \mathrm{~L}$ group (Fig. 3). These three groups constitute a basic repeating unit $(2 \mathrm{R}, 2 \mathrm{R}, 2 \mathrm{R} 1 \mathrm{~L})$
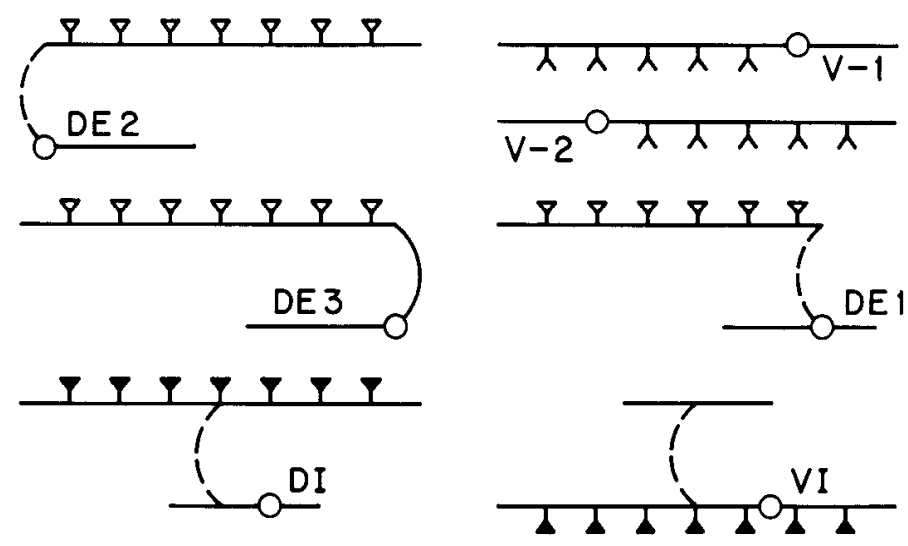

\section{$\longleftarrow$ anterior}

Figure 2. Diagram showing the geometry of the seven classes of motoneurons in the ventral and dorsal nerve cords of Ascaris. Circles represent the cell bodies of motoneurons in the ventral cord. Horizontal lines represent processes in the ventral and dorsal nerve cords (anterior is to the left), curved vertical lines represent commissures: solid for left-handed commissures, dashed for right-handed commissures $(V-1$ and $V-2$ cells have no commissure) $\wedge$, neuromuscular output zone; $Y$, excitatory output; 1 inhibitory output.
A B

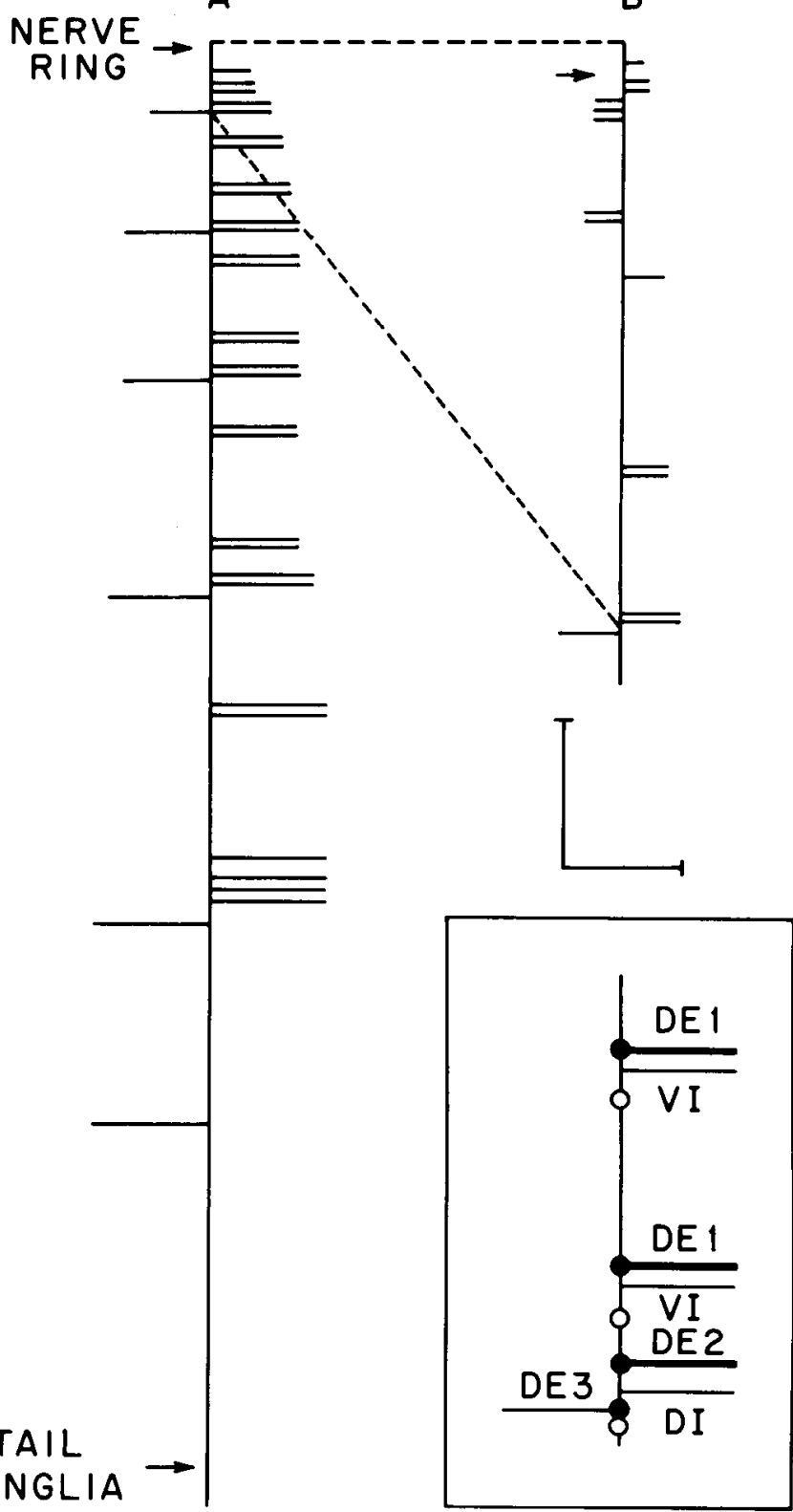

Figure 3. Diagram of the ventral nerve cord of a female Ascaris showing the position, length, and handedness of motoneuron commissures. Commissure handedness and length are indicated, respectively, by the direction and length of the horizontal line. (The most common pattern of handedness is shown. Minor variations have also been observed (A. O. W. Stretton, unpublished observation).) $A$. The vertical line represents the entire length of the ventral nerve cord; horizontal lines represent the commissures. The average relative position of the commissures in collagenase-treated animals, normalized to take into account differences in total length of worms, is shown $(n=26)$. Commissure length measurements were taken as the distance from ventral nerve cord to the lateral line in a single animal. Arrows show the positions of the nerve ring and tail ganglia. $B$. The anteriormost $5 \%$ of the ventral nerve cord expanded 8 -fold. The six commissures anterior to the first repeating unit and two commissures ( $1 \mathrm{~L}$ and $1 \mathrm{R}$, not shown in diagram), located posterior to the $1 \mathrm{~L}$ which follows the fifth repeat, are not considered in this paper. The vertical scale bar represents $10 \%$ of the total worm length the horizontal scale is $4 \mathrm{~mm}$. Inset, Diagram of a single repeating unit of commissures. Circles in the ventral nerve cord represent the positions of motoneuron cell bodies $(O$, excitatory motoneurons: 1 inhibitory motoneurons). Relative commissure thickness is also indicated. Commissures are labeled with their motoneuron class based upon (1) commissure handed ness, (2) position in the repeating unit, (3) relative thickness, and (4) whether the commissure connects directly with its cell body in the ventral nerve cord. 
that occurs five times along the length of the animal (Stretton et al., 1978 ). In the fifth repeating unit the second $2 R$ group merges with the $2 \mathrm{R} 1 \mathrm{~L}$ group to give a four to the right, one to the left (4R1L) group. Posterior to this there is an additional single left-handed commissure. In the first repeating unit, the initial $2 \mathrm{R}$ is reflected to the left and there is an additional (1R) commissure. Neurons within the first three repeats have been identified anatomically (Stretton et al., 1978); each $2 \mathrm{R}$ consists of a DE1/VI and each $2 \mathrm{R} 1 \mathrm{~L}$ includes $\mathrm{DE} 2, \mathrm{DI}$, and DE3 neurons. Physiological studies of these neurons in the first three segments have demonstrated that all DE cells are excitatory, whereas all DI and VI cells are inhibitory (Walrond et al., 1985).

The results obtained assaying CAT within 16 groups of commissures from a single female Ascaris are shown in Figure 4. Measurable levels of enzyme activity were observed in all of the strips of hypodermis assayed, whether they contained commissures or not. Depending on their identity, some of the strips containing commissures have clearly elevated CAT activity compared to adjacent strips which contain no commissure. In each repeating unit, four of the seven commissures have elevated CAT activity. The other three commissures do not have elevated CAT activity. Commissures with elevated CAT are identified as DE1 (the thick members of the first two 2R groups), DE2 (thick right-handed member of the 2R1L group), and DE3 (the single left-handed commissure). Those without CAT are identified as VI (thin members of the first two $2 \mathrm{R}$ groups) and DI (thin right-handed commissure in the $2 \mathrm{R} 1 \mathrm{~L}$ group).

The results of many such localization experiments on each group of commissures are summarized in Table I. There was fairly large variation in the absolute levels of enzyme found in the excitatory motoneurons. Furthermore, CAT is found throughout the hypodermis and contributes significant background activity against which the neuronal contribution has to be assessed. The level of CAT in hypodermis varies systematically with body location (see below) and in some regions is so high that the neuronal involvement is not detectable. We therefore established arbitrary criteria in order to decide whether inclusion of a commissure in the hypodermal strip elevated the measured CAT activity. By the criterion that CAT activity was elevated at least 2 times over the hypodermal control and that for commissure pairs, one commissure contained at least 5 times as much CAT as the other, elevated CAT was observed in 281 commissures. By the more stringent criterion that CAT activity was increased at least 5 times compared to the hypodermal control, elevated CAT was found in 180 commissures.

Of 206 experiments on pairs of right-handed commissures, CAT was observed by the first criterion in one commissure but not in the other in 184 cases. In no experiments did both members of a righthanded pair appear to contain CAT. In 173 experiments in which $\mathrm{DE} 1 / \mathrm{VI}$ pairs were dissected from ventral hypodermis, the CATcontaining commissure was more anterior 105 times and more posterior 8 times; in all but 2 of the former, and in all 8 of the latter experiments the commissure with elevated CAT was clearly noted as being the thicker member of the pair. The CAT-containing commissure was anterior in 18 of 22 experiments in which DE1/VI pairs were dissected from dorsal hypodermis. (There is little difference in the thickness of DE 1 and $\mathrm{VI}$ commissures in dorsal hypodermis.) In

Figure 4. CAT activity in 35 commissures from a single animal. Graphical representation of CAT assays for 35 commissures and controls from a single female Ascaris. Each bar represents the assay of a single hypodermal strip; open bars represent strips containing commissures, and solid bars represent strips containing no commissure (hypodermal control). All commissures are recorded in strict anterior-posterior order and are separated into $2 \mathrm{R}$ and $2 \Gamma 1 \mathrm{~L}$ groups. CAT activity is indicated by the length of the bar: to the right for right-handed commissures and to the left for the single left-handed commissures. Tk indicates that the commissure was seen at the time of dissection to be the thicker of the two commissuies. Assays were performed at $\mathrm{pH} 7.0$ in $5 \mu \mathrm{l}$ for $43 \mathrm{hr}$. Total extractable counts $=1.27 \times 10^{5}$ counts per minute; blank $=460$ counts per minute. In this experiment borohydride treatment was not included as part of the termination procedure.

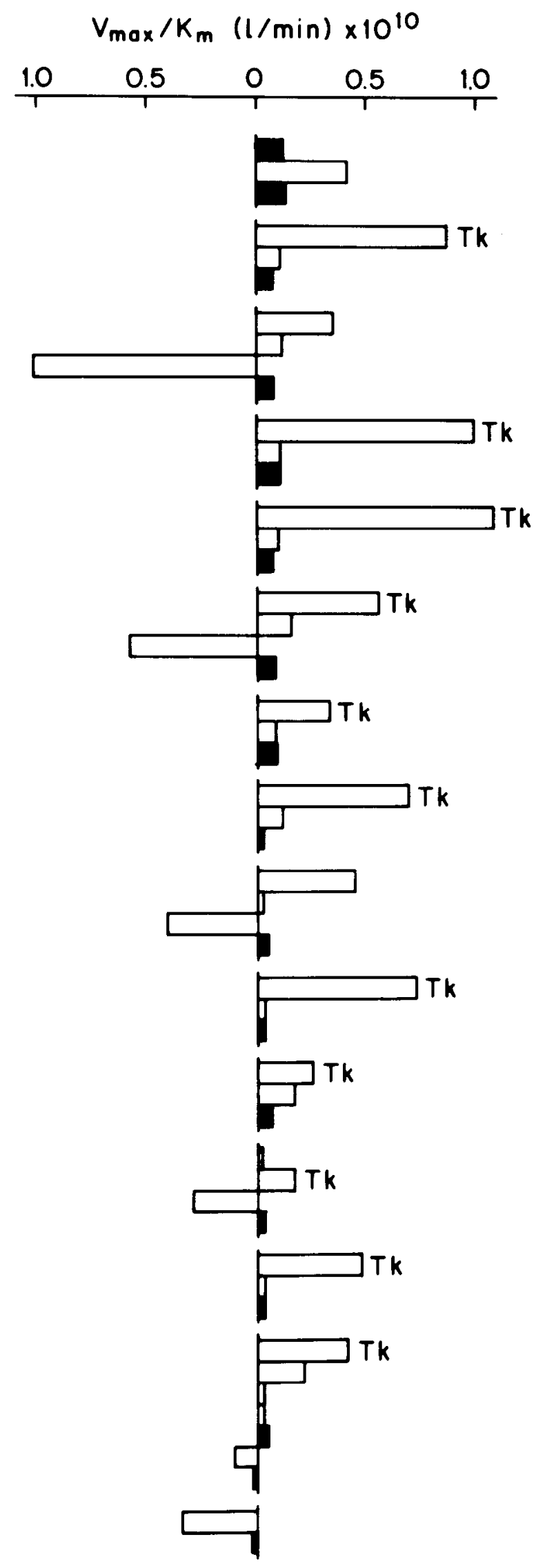




\section{TABLE |}

Repeats of CAT localization in single commissures

This table combines (1) experiments from which assay procedure 1 ("Materials and Methods") was established (13 worms, 145 commissure groups), (2) assays with procedure 1 ( 7 worms, 114 commissure groups), and (3) assays with procedure 2 (10 worms, 100 commissure groups). The first two columns identify the CAT-containng commissure by repeating unit and by commissure group: $1 \mathrm{R}, 2 \mathrm{R}$, and $4 \mathrm{R}$ - groups containing one, two, or four right-handed commissures, respectively, and $1 \mathrm{~L}$ and $2 \mathrm{~L}-$ groups containing left-handed commissures. Columns 3 and 4 record the number of experiments in which elevated CAT was observed in a single commissure by two criteria: Criterion 1, which required, for paired commissures, that $E>$ $2 \times H y$ and $E-H y>5 \times(I-H y)$ and for single commissures $E>2 \times$ $H y$; and Criterion 2, which required $E>5 \times H y$ for all commissure groups. $E$ represents CAT activity of hypodermal strips containing excitatory motoneuron commissures, I represents activity of strips containing inhibitory motoneuron commissures, and Hy represents CAI activity of control strips without a commissure. Column 5 records the total number of experiments in which a commissure group was dissected and assayed. For comparison, assays of the $4 R$ group in the fifth repeating unit were recorded as two $2 R$ pairs. Only those data collected during preliminary experiments which revealed elevated CAT activity in excitatory motoneurons (47 commissure groups) are included in the total.

\begin{tabular}{|c|c|c|c|c|}
\hline \multirow{3}{*}{$\begin{array}{c}\text { Repeating } \\
\text { Unit }\end{array}$} & \multirow{3}{*}{$\begin{array}{c}\text { Commissure } \\
\text { Group }\end{array}$} & \multicolumn{3}{|c|}{ Number of Experiments } \\
\hline & & \multicolumn{2}{|c|}{ E Neuron CAT elevated by } & \multirow{2}{*}{ Tota } \\
\hline & & Criterion 1 & Criterion 2 & \\
\hline \multirow[t]{5}{*}{ । } & $2 \mathrm{~L}$ & 0 & 0 & 2 \\
\hline & $1 R$ & 2 & 0 & 5 \\
\hline & $2 \mathrm{R}$ & 2 & 0 & 7 \\
\hline & $2 \mathrm{R}$ & 2 & 2 & 6 \\
\hline & $1 \mathrm{~L}$ & 10 & 5 & 13 \\
\hline \multirow[t]{4}{*}{$\|$} & $2 R$ & 13 & 10 & 16 \\
\hline & $2 \mathrm{R}$ & 17 & 12 & 19 \\
\hline & $2 \mathrm{R}$ & 20 & 8 & 22 \\
\hline & $1 \mathrm{~L}$ & 26 & 17 & 26 \\
\hline \multirow[t]{4}{*}{$\|$} & $2 \mathrm{R}$ & 20 & 15 & 21 \\
\hline & $2 \mathrm{R}$ & 23 & 18 & 23 \\
\hline & $2 \mathrm{R}$ & 22 & 14 & 22 \\
\hline & $1 \mathrm{~L}$ & 33 & 20 & 33 \\
\hline \multirow[t]{4}{*}{ IV } & $2 \mathrm{R}$ & 18 & 13 & 18 \\
\hline & $2 R$ & 14 & 12 & 15 \\
\hline & $2 \mathrm{R}$ & 13 & 7 & 14 \\
\hline & $1 \mathrm{~L}$ & 15 & 8 & 15 \\
\hline \multirow[t]{6}{*}{ V } & $2 \mathrm{R}$ & 7 & 6 & 9 \\
\hline & $4 \mathrm{R}$ & 7 & 6 & 7 \\
\hline & & 6 & 2 & 7 \\
\hline & $1 \mathrm{~L}$ & 5 & 2 & 5 \\
\hline & $1 L$ & 6 & 3 & 7 \\
\hline & Total & $\overline{281}$ & $\overline{180}$ & $\overline{332}$ \\
\hline
\end{tabular}

57 experiments in which DE2/DI pairs were dissected from ventral hypodermis, the CAT-containing commissure was more anterior 37 times; in 10 of the 20 experiments in which the commissure with CAT was posterior, it was noted to be thicker. For DE2/DI pairs dissected from dorsal hypodermis, the CAT-positive commissure was anterior in only 4 of 10 experiments.

Selective localization of CAT in one member of right-handed pairs or in single left-handed commissures has been observed repeatedly (at least five times and in most cases many more; Table 1) for all of the groups of commissurcs in the second through the fifth repeating units as well as for the single commissure to the left at the end of the first repeating unit. CAT has also been selectively localized to three additional commissures in the first repeating unit, although these localizations have been successfully repeated only twice for each group. The fraction of experiments in which selective localiza tion is observed is lower in the anterior part of the animal. We believe that this is partly due to damage produced by overdigestion with the protease; successful localization was achieved only when the digestion time was deliberately kept short. In addition, these commissures are shorter and closer together and arc thcrcfore more difficult to dissect.

No selective localization has been observed for the $2 \mathrm{~L}$ group in the first repeating unit, or for the $3 \mathrm{~L}, 2 \mathrm{R}$, or $1 \mathrm{R}$ groups anterior to the first repeat. The level of CAT in the hypodermis anterior to the single commissure to the right in the first repeating unit rises rapidly to a very large peak in the tip of the head (data not shown). Even if the CAT level in single commissures were equivalent to that found in more posterior excitatory motoneuron commissures, it could not be reliably measured as an increase over the hypodermal control. The localization of CAT in hypodermis of the tip of the head will be more thoroughly addressed in a separate publication (C. D. Johnson and A. O. W. Stretton, manuscript in preparation).

In order to quantitate the level of CAT activity measured in excitatory motoneuron commissures under optimized assay conditions (procedure?, "Materials and Methods"), CAT activities were measured in 12 repeating units from five different animals (Table II). Commissures of DE1 motoneurons contain the largest amount of CAT: $\sim 2.5 \times 10^{-10}$ liters/min. Those of DE2 motoneurons contain about half this amount, and DE3 commissures contain two-thirds. Commissures of $\mathrm{VI}$ and DI motoneurons do not significantly add to the level of CAT found in the hypodermis, which is $\sim 0.25 \times 10^{-10}$ liters/min. The high ratio of standard deviation to activity (Table II) results from the occurrence of occasional assays in which CAT level is unusually large (Fig. 5). One explanation is that the protease digestion used to remove the muscle cell layer prior to dissection or the dissection itself generally results in the loss of a large fraction of the neuronal CAT. Alternatively, since the commissures are not homogenized, substanlial amounts of enzyme may be inefficiently assayed because it is trapped within the tissue. The abnormally large CAT assay values would then more accurately reflect minimum in vivo enzyme levels in excitatory motoneuron commissures. A third explanation is that CAT synthesis or transport into the commissure is not constant in time or that different animals or different cells in an animal may synthesize CAT at different rates, in which case, the high variability would accurately reflect the localization of CAT in different commissures.

To be sure that the low level of activity observed in single strips of hypodermis was authentic CAT required careful attention to assay conditions and controls. First, it was necessary to assure the synthesis of sufficient ACh to be measured; second, interference by alternate products of choline metabolism had to be eliminated. in most early experiments, hypodermal strips were frozen and thawed in $100 \mu \mathrm{l}$ of $\mathrm{H}_{2} \mathrm{O}$ before being assayed in $5 \mu \mathrm{l}$ at $\mathrm{pH} 7.0$ (procedure 1; e.g., Fig. 4). This procedure was adopted because it yielded differential localization of CAT activity in excitatory motoneuron commissures (compared to inhibitory commissures and hypodermal

\section{TABLE \|}

Average CAT activity of single commissures

CAT activity was measured in 12 repeating units from five different animals The average $( \pm S D) V_{\max } / K_{m}$ values obtained for hypodermal strips from $2 \mathrm{R}$ groups $(n=24)$ and for 2R1L groups $(n=12)$ are presented. Neuronal CAT activity was obtained by subtracting the activity measurcd in adjaccnt control strips which contain no commissure. All commissures were assayed in $10 \mu$ l at $\mathrm{pH} 8.1$ for 30 to $51 \mathrm{hr}$.

\begin{tabular}{lcr} 
Commissure & CAT Activity & \multicolumn{1}{c}{ Neuronal CAT Activity } \\
\hline DE1 & $2.65 \pm 1.81 \times 10^{-10}$ & $2.43 \pm 1.79 \times 10^{-10}$ \\
VI & $0.26 \pm 0.16 \times 10^{-10}$ & $0.05 \pm 0.11 \times 10^{-10}$ \\
Hy & $0.21 \pm 0.12 \times 10^{-10}$ & \\
DE2 & $1.33 \pm 0.63 \times 10^{-10}$ & $1.04 \pm 0.55 \times 10^{-10}$ \\
DI & $0.20 \pm 0.12 \times 10^{-10}$ & $(-) 0.05 \pm 0.11 \times 10^{-10}$ \\
DE3 & $1.96 \pm 1.24 \times 10^{-10}$ & $1.66 \pm 1.19 \times 10^{-10}$ \\
Hy & $0.26 \pm 0.15 \times 10^{-10}$ & \\
\hline
\end{tabular}




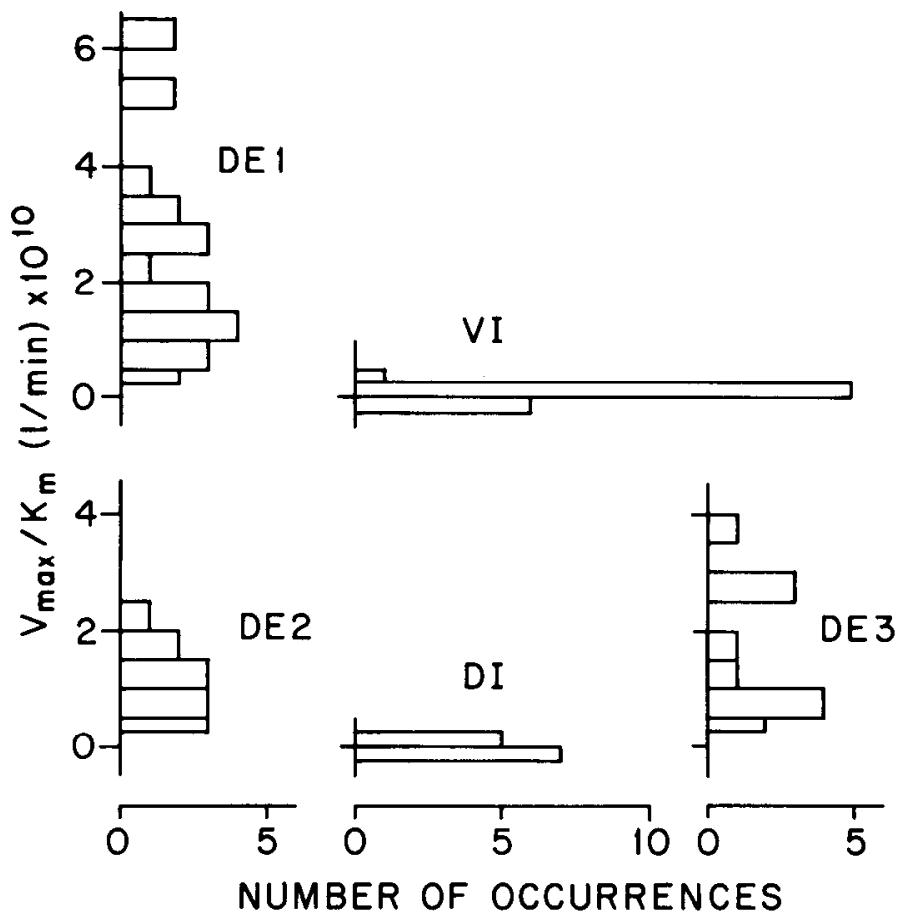

Figure 5. Variability of commissural CAT assay: Histogram of CAT measured in commissures of 12 repeating units from five different animals (second, third, and fourth repeating units). All assays were performed in $10 \mu \mathrm{l}$ at $\mathrm{pH}$ 8.1. Assay length varied from 30 to $51 \mathrm{hr}$. Data were converted to $V_{\max } / K_{\mathrm{m}}$ units, and the CAT activity measured in the adjacent hypodermal strip containing no commissure was subtracted.

controls). In attempting to increase the measured activity by eliminating the freeze-thaw wash or by assaying at $\mathrm{pH} 8.1$ (close to the $\mathrm{pH}$ optimum of nerve cord CAT activity; unpublished observations), it was observed (Fig. 6A) that the apparent CAT activity of hypodermal controls was stimulated to such an extent that the CAT activily in the excitatory moloneuron commissures no longer satisfied either criterion 1 or criterion 2 for localization. Furthermore, an appreciable portion of the apparent CAT activity in all of the strips was not acetyl-CoA dependent (Fig. $6 B$ ) and was insensitive to acetylcholinesterase treatment (data not shown). These results suggested that the CAT assay was monitoring an alternative product of choline metabolism in addition to ACh. Because betaine aldehyde, the product of choline dehydrogenase-catalyzed oxidation of choline, was a likely candidate for this alternative product, we tested the effect of post-assay treatment with sodium borohydride. Borohydride had been shown to reduce betaine aldehyde back to choline (C. D. Johnson and R. S. Pratt, unpublished observation), after which it would then be phosphorylated by choline kinase and would not be extracted along with ACh. As can be seen from Figure $6 \mathrm{C}$, borohydride treatment restored the clear selective localization of CAT to excitatory motoneuron commissures. At higher concentrations $>10$ $\mathrm{mm}$ ) borohydride also reduced extractable ACh (data not shown). The activity measured by utilizing a post-assay borohydride treatment was completely acetyl-CoA dependent (Fig. 6D) and sensitive to acetylcholinesterase (data not shown) and thus appears to reprosent CAT activity only.

In order to be assured that the CAT activity survived the lengthy incubations necessary to synthesize measurable $\mathrm{ACh}$, we performed the experiment shown in Figure 7. Five strips of hypodermis containing a single type of commissure were pooled and incubated with substrates in $50 \mu \mathrm{l}$. $\wedge \mathrm{t}$ various times, $5-\mu \mathrm{l}$ samples of the incubation media were removed and assayed for conversion of $\left[{ }^{3} \mathrm{H}\right]$ choline to $\left[{ }^{3} \mathrm{H}\right] \mathrm{ACh}$. Figure 7 shows the increase in $\left[{ }^{3} \mathrm{H}\right] \mathrm{ACh}$ for samples of the pool containing excitatory (DE1) motoneuron commissures, inhibitory (VI) commissures, hypodermal strips without commissures, and no

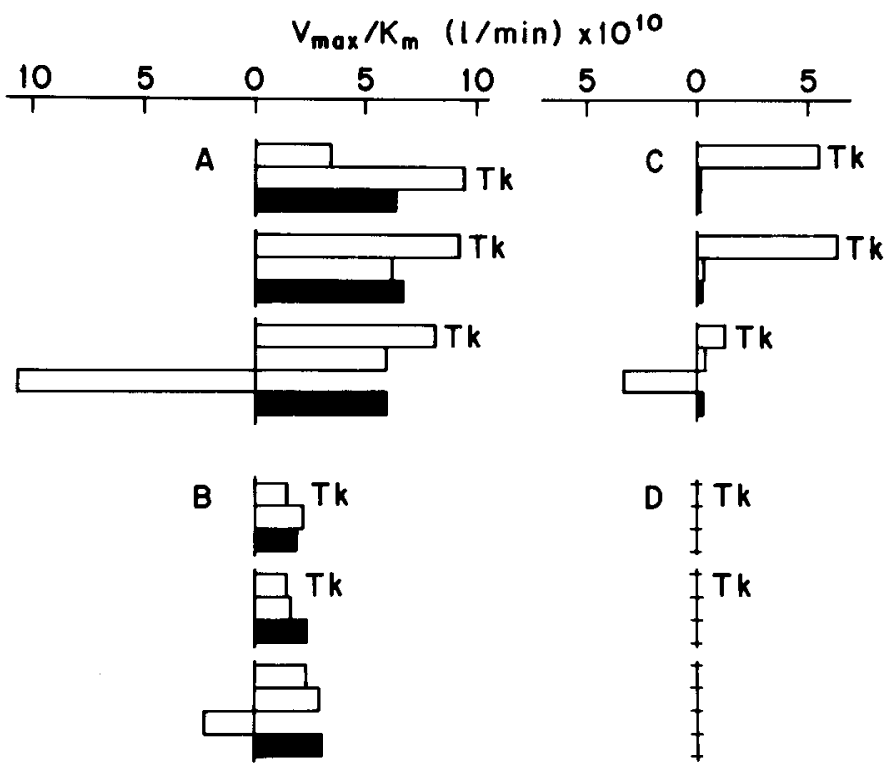

Figure 6. CAT assay controls. Graphical representation of CAT assay controls which demonstrates acetyl-CoA dependence of CAT activity and illustrates the necessity for post-assay borohydride treatment. Each assay condition was used to measure activity in strips of hypodermis from a complete third repeating unit of a different animal. Graphical form and symbols are as in Figure 4. A, CAT assay without borohydride treatment (+acetyl-CoA, no $\mathrm{NaBH}_{4}$ ). This condition measures both CAT and choline dehydrogenase. $B$, Choline dehydrogenase activity measured in the absence of CAT activity (no acetyl-CoA, no $\mathrm{NaBH}_{4}$ ). Choline dehydrogenase is not localized to neurons. $C$, Standard $\mathrm{C} \wedge \mathrm{T}$ assay condition (+acctyl CoA, $+\mathrm{NaBH}_{4}$ ). $D$, acetyl-CoA dependence of standard CAT assay condition (no acetyl-CoA, $+\mathrm{NaBH}_{4}$ ). The values obtained with this condition (average, $0.001 \pm 0.001 \times 10^{-10}$ liters $/ \mathrm{min}$ ) fail to register on the graph. All assays were performed in $10 \mu \mathrm{l}$ at $\mathrm{pH} 8.1$ for $51 \mathrm{hr}$. Total extractable counts per minute and duplicate blanks, respectively, were: $A, 70731$ and 266, 276; $B$, 65042 and 203,$197 ; C, 69856$ and 245, 255; D, 65694 and 168, 192.

lissue. In all cases the increase is close lo linear with time, indicating that the CAT activity is sufficiently stable to justify the use of long incubations. The rate of $A C h$ synthesis in the pool containing DE1 commissures is about 10 times that observed in pools of $\mathrm{Vl}$ commissures or in the hypodermal control (Fig. 7A). The activity measured in $\mathrm{VI}$ commissures is identical to that in control hypodermis; both of these activities, however, are significantly greater than the extremely low level of apparent ACh synthesis measured in the notissue blank (Fig. 7B)

Further evidence that the product being monitored is indeed $\mathrm{ACh}$ was obtained by high voltage paper electrophoretic analysis. The final sample of the incubation media of the experiment described above and in Figure 7 was treated with borohydride and subjected to electrophoresis at $\mathrm{pH} 1.9$ as described by Hildebrand et al. (1971). All of the samples contained a peak of radioactivity at the position expected for ACh based upon a comparison with authentic unlabeled standards and its position relative to the main peak of unreacted $\left[{ }^{3} \mathrm{H}\right]$ choline. The fractional conversion determined by electrophoretic analysis is very similar to that determined by the extraction assay. For DE.1, ACh represented $8.4 \%$ of the extractable products observed in the elcctrophorcsis run; it represented $7.8 \%$ of the total extractable counts per minute at the final time point in Figure 7. The level of ACh synthesis determined by electrophoretic analysis in hypodermal strips containing $\mathrm{VI}$ commissures and in hypodermal controls was, in each case, about $10 \%$ of that seen in $\mathrm{DE} 1$. This is also in good agreement with the results of the extraction assay. Finally, even the no-tissue blank had a small peak at the position of $\mathrm{ACh}$ in agreement with the slight rise in blank observed in Figure 7.

As a final control, aliquots of the labeled compounds extracted 
Figure 7. Linearity with time of commissure assay. Five strips of hypodermis, each containing a DE1, a VI, or no commissure, were combined and incubated in $50 \mu \mathrm{l}$ at $\mathrm{pH}$ 8.1. At various times $5-\mu \mathrm{l}$ samples were removed (the strips were left behind in the remaining medium), diluted to $100 \mu \mathrm{l}$, and treated with borohydride. One $50-\mu \mathrm{l}$ aliquot was used for selective extraction of ACh, with another used to determine the total extractable counts per minute. $A$, Counts per minute were extractable as $A C h$ in the incubations of hypodermal strips containing DE1 commissures $(\Theta)$, VI commissures $(\Delta)$, or no commissure $(O)$, and in the no tissueblank $(X)$. The dashed line to the open circle represents $5 \mu$ l of assay mixture removed from contact with hypodermal strips after the third time point. By comparing the ACh increase in this sample to that which remained in contact with the strips, we estimate that $89 \%$ of the assayable CAT activity in commissures is soluble. $B$, Counts per minute were extractable as $A C h$ expanded 5 times, compared to $A$. Total extractable counts per minute was $\sim 5.5 \times 10^{4}$ in all cases.
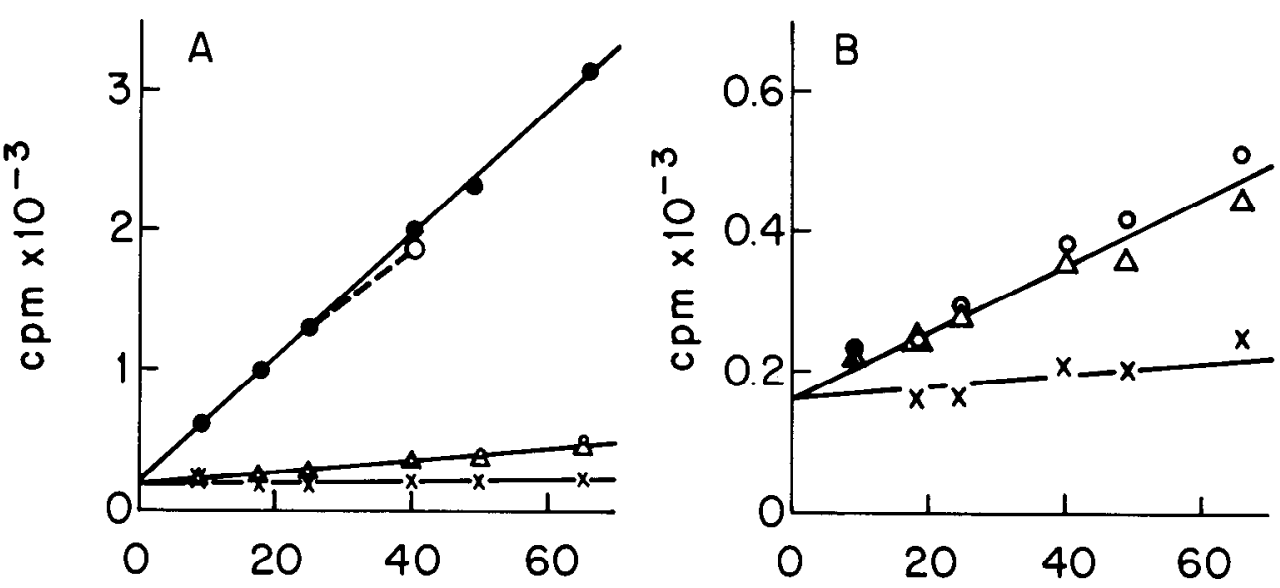

TIME (hrs)

from the paper after electrophoretic analysis were examined for extraction into scintillation fluid containing tetraphenylboron (data not shown). As expected, in all cases the product which had the electrophoretic mobility of ACh was extracted, and this extraction was unaffected by choline kinase either alone or in combination with borohydride. Extraction was completely suppressed by treatment with acetylcholinesterase and choline kinase. By all of these criteria, the reaction product is authentic $\mathrm{ACh}$.

\section{Discussion}

In this paper, we describe the localization of CAT, the enzyme which synthesizes the putative neurotransmitter ACh within the commissures of identified motoneurons from the large parasitic nematode Ascaris lumbricoides var. suum. The assay we used to measure CAT is a micromodification of a published single-vial biphasic liquid extraction assay (Rand and Johnson, 1981) which monitors the conversion of $\left[{ }^{3} \mathrm{H}\right]$ choline to acetyl $-\left[{ }^{3} \mathrm{H}\right]$ choline by selective extraction of $\mathrm{ACh}$ into scintillation fluid containing tetraphenylboron. Compared to high voltage paper electrophoresis which has been used to perform this separation in the past (e.g., Hildebrand et al., 1974), the level of post-assay manipulation has been greatly reduced such that the large number of determinations involved in this study could be performed with relative ease. In order to measure the small amount of CAT in single commissures, we increased the sensitivity of the method by (1) decreasing the volume and (2) increasing the incubation time under conditions where the enzyme is stable. The absolute sensitivity appears eventually to be limited by the low level of nonenzymatic ACh synthesis we observe in notissue blanks (Fig. 7) which is $\sim 0.5 \times 10^{-11}$ liters $/ \mathrm{min}$ in a $10-\mu$ l incubation volume.

During the course of these experiments we found that, in its simplest form, the extraction assay is sensitive to interference by betaine aldehyde, the product of choline oxidation (both spontaneous and choline dehydrogenase catalyzed). This interference had not been emphasized previously (Rand and Johnson, 1981), since the tissues in which CAT was assayed did not contain appreciable choline dehydrogenase activity, whereas in the Ascaris tissue, there are significant levels of this enzyme. We have eliminated this inter ference by routinely including borohydride treatment in the postassay termination procedure. It should be noted that, unless an alkaline or cholinesterase-hydrolyzed control is performed, high voltage paper electrophoresis assay of ACh is also sensitive to this interference since betaine aldehyde and $\mathrm{ACh}$ migrate electrophoretically to almost identical positions.

In addition to the availability of a sensitive CAT assay, two other factors combine to allow determination of CAT localization in identified motoneurons. First, extensive anatomical studies of Ascaris motoneurons (Stretton et al., 1978) by reconstruction of serial sections had examined the correlation of commissure position with identified motoneurons. Second, a method for removing the muscle cells which cover the hypodermis and the commissures by injecting intact animals with proteases has been developed. During the course of preliminary experiments, it became clear that the level of protease used to remove muscle can affect the amount of CAT measured in commissures. This is most obvious when hypodermal strips from animals in which the hypodermis was separated from the cuticle or contained visible breaks were assayed. Such assays were routinely unsuccessful. Overdigestion problems are particularly acute in commissures of the first repeating unit. Perhaps because the muscle layer which covers these commissures is thinner than in more posterior regions of the worm, these commissures are often overdigested before the muscle covering more posterior commissures has dissociated. We believe that overdigestion explains the relative difficulty in detecting selective localizations of CAT in the anterior part of the worm. Overdigestion is not as serious a problem in the second through fifth repeats, and as seen in Table I, localization in this part of the animal was much more reproducible.

CAT activity has been determined in all of the commissures in the second through the fifth repeating units as well as in the last three commissures of the first repeating unit (Table I). These include commissures from six DE1, three DE2, and three DE3 motoneurons that had previously been identified as excitatory motoneurons by physiological experiments (Walrond et al., 1985); all of them contain CAT. The commissures of six VI and three DI motoneurons which had been identified as inhibitory motoneurons do not contain CAT.

Cells with commissures in the fourth and the fifth repeating units had not been previously identified by anatomical or physiological means. One conclusion of these studies, therefore, is that those cells in the fourth and fifth repeating units which contain CAT are presumptive excitatory motoneurons, whereas those which contain no CAT are presumptive inhibitory motoneurons. The pattern of commissures previously observed in the first three repeating units of Ascaris (three right-handed pairs of commissures, each containing one excitatory and one inhibitory motoneuron commissure, followed 
by a single excitatory commissure to the left) appears on the basis of CAT localization to continue into the fourth and fifth repeating units.

The level of CAT selectively localized in excitatory commissures averages about $2 \times 10^{-10}$ liters/min in $V_{\max } / K_{\mathrm{m}}$ units. If we assume a $K_{\mathrm{m}}$ of $5 \mu \mathrm{M}$, then this level of CAT represents $V_{\max }=10^{-9} \mu \mathrm{mol} /$ min under the conditions of our assay. The value taken for the $K_{m}$ is that measured for nematode CAT purified from Caenorhabditis elegans (Rand and Russell, 1985) and assayed under identical conditions. In order to arrive at an estimate of the number of CAT molecules in a commissure, we have compared our assay procedure to that of Fonnum (1975). We found that under the latter conditions the $V_{\max }$ of nematode CAT was 134 times larger than that which we obtained with our assay conditions. Purified CAT from several species has been shown, using the Fonnum (1975) assay, to have a specific activity of $\sim 100 \mu \mathrm{mol} / \mathrm{min} / \mathrm{mg}$ of protein and $M_{\mathrm{r}}$ of $\sim 70,000$ (e.g., Rossier, 1976; Eckenstein and Thoenen, 1982; Cozzari and Hartman, 1983; Hersh et al., 1984; Rand and Russell, 1985). Using these values we can calculate that the piece of commissure we have assayed contains $\sim 10^{7}$ molecules of CAT

Hildebrand et al. (1974) have measured the CAT activity of single cholinergic sensory neurons in the lobster. These authors found $V_{\max }$ $=2.8 \times 10^{-7} \mu \mathrm{mol} / \mathrm{min} / \mathrm{cm}$ of axon length. Under the conditions of their assay we find that the $V_{\max }$ of nematode CAT is 18 times larger than under our assay conditions. In addition, the axons they were measuring are $25 \mu \mathrm{m}$ in diameter, whereas the commissures of Ascaris are only $\sim 10 \mu \mathrm{m}$ in diameter and $0.4 \mathrm{~cm}$ long; if Ascaris neurons contained the same concentration of CAT, we would have expected $3 \times 10^{-9} \mu \mathrm{mol} / \mathrm{min} / \mathrm{commissure}$, suggesting that the CAT activity in lobster neurons and Ascaris excitatory motoneuron commissures is similar.

Based upon the localization of CAT, we suggest that all three classes of dorsal excitatory (DE) motoneurons in Ascaris utilize ACh as a neurotransmitter. This suggestion is supported by the observation (Johnson and Kass, 1978; Walrond and Stretton, 1985) that the synapses of the DE motoneurons made both to muscle cells and to other neurons are sensitive to $d$-tubocurarine. Earlier studies by del Castillo et al. (1963), which examined the electrical responses due to localized iontophoresis of ACh onto various regions of Ascaris muscle cells and the effects of drugs on these responses, also support the suggestion that $\mathrm{ACh}$ is an excitatory transmitter at nematode neuromuscular junctions.

Two classes of motoneurons in Ascaris (V-1 and V-2; Stretton et al., 1978) have no commissure and cannot be examined with the techniques used to dissect single neurons in this paper. The shape of these cells, their positions in nerve cords, and their synaptic connections in the ventral nerve cord parallel those of the DE motoneurons in the dorsal nerve cord (Walrond and Stretton, 1985). We believe, therefore, that they are the ventral excitatory motoneurons and that they will also use ACh as their neurotransmitter. Based upon the present evidence, the neurotransmitter of the inhibitory motoncurons ( $\mathrm{Vl}$ and $\mathrm{DI}$ ) is not $\mathrm{ACh}$. Sincc Ascaris muscle is known to be hyperpolarized by 4 -aminobutyric acid, it has been suggested that GABA may be the inhibitory transmitter, but direct evidence is lacking (del Castillo et al., 1964).

During studies of CAT localization in commissures, we were surpriscd to find that CAT is also localized in the hypodermis and is especially concentrated in hypodermis in the anteriormost $0.1 \mathrm{~cm}$ (C. D. Johnson and A. O. W. Stretton, manuscript in preparation). What role CAT and the ACh it may synthesize in the hypodermis play in the physiology of nematodes is not yet clear. If hypodermal $A C h$ wore to bo relcascd, it might causc tonic contraction of the somatic musculature. The existence of a tonic source of ACh release in Ascaris was also suggested by del Castillo et al. (1963), who showed that $d$-tubocurarine hyperpolarized muscle cells in the absence of applied ACh.

The function of ACh is also bcing activcly studied, utilizing biochemical and genetic techniques in the small soil nematode Cae- norhabditis elegans (Brenner, 1974; Russell et al., 1977; Lewis et al., 1980a, b; Culotti et al., 1981; Johnson et al., 1981; Johnson and Russell, 1983; Rand and Russell, 1984, 1985). Although C. elegans is too small to be useful for localization studies by single-cell dissection, its nervous system is very similar to that of Ascaris. In particular, the ventral and dorsal nerve cords of $C$. elegans contain seven classes of motoneurons the shapes of which are analogous to those of Ascaris (White et al., 1976; for the correlation of neuron nomenclature in C. elegans and in Ascaris, see Stretton ct al., 1978). Mutants of the gene cha-1 are deficient in CAT (Russell et al., 1977; Rand and Russell, 1984). Mutants carrying severe alleles of cha-1 move in a coiling uncoordinated manner, consistent with the notion that they are defective in neural control of locomotion. If the motoneurons analogous to DE1, DE2, and DE3 are also cholinergic in $C$. elegans, the function of these cells will be one site at which a defect in CAT might be expressed.

\section{References}

Brenner, S. (1974) The genetics of Caenorhabditis elegans. Genetics 77: 71-94.

Cozzari, C., and B. K. Hartman (1983). Choline acetyltransferase: Purification procedure and factors affecting chromatographic properties and enzyme stability. J. Biol. Chem. 258: 10013-10019.

Culotti, J. G., G. von Ehrenstein, M. R. Culotti, and R. L. Russell (1981) A second class of acetylcholinesterase-deficient mutants of the nematode Caenorhabditis elegans. Genetics 97: 281-305.

del Castillo, J., W. C. deMello, and T. Morales (1963) The physiological role of acetylcholine in the neuromuscular system of Ascaris lumbricoides. Arch. Int. Physiol. Biochim. 71: 741-757.

del Castillo, J., W. C. deMello, and T. Morales (1964) Inhibitory actıon of GABA on Ascaris muscle. Experientia 20: 141

Eckenstein, $F_{\text {., }}$ and $\mathrm{H}$. Thoenen (1982) Production of specific antisera and monoclonal antibodies to choline acetyltransferase: Characterization and use for identification of cholinergic neurons. EMBO J. 1: 363-368.

Fonnum, F. (1975) A rapid radiochemical method for determination of choline acetyltransferase. J. Neurochem. 24: 407-409.

Hersh, L. B., B. H. Wainer, and L. P. Andrews (1984) Multiple isoelectric and molecular weight variants of choline acetyltransferase: Artifact or real. J. Biol. Chem. 259: 1253-1258.

Hesse, R. (1892) Uber das Nervensystem von Ascaris megalocephala. Z. Wiss. Zool. 54: 548-568.

Hildebrand, J. G., D. L. Barker, E. Herbert, and E. A. Kravitz (1971) Screening for neurotransmitters: A rapid radiochemical procedure. J. Neurobiol. 2: $231-246$.

Hildebrand, J. G., J. G. Townsel, and E. A. Kravitz (1974) Distribution of acetylcholine, choline, choline acetyltransferase and acetylcholinesterase in regions and single axons of the lobster. J. Neurochem. 23: 951-963.

Johnson, C. D., and I. S. Kass (1978) Acetylcholine function in the nematode Ascaris. Soc. Neurosci. Abstr. 4: 197

Johnson, C. D., and R. L. Russell (1983) Multiple molecular forms of acetylcholinesterase from the nematode Caenorhabditis elegans. J. Neurochem. 41: 30-46.

Johnson, C. D., and A. O. W. Stretton (1977) Cellular localization of choline acetyltransferase in motorneurons from Ascaris. Neurosci. Abstr. 3: 180

Johnson, C. D., and A. O. W. Stretton (1980) Neural control of locomotion in Ascaris: Anatomy, physiology and biochemistry. In Nematodes as Biological Models, B. M. Zuckerman, ed., Vol 1, pp. 159-195, Academic Press, Inc., New York.

Johnson, C. D., J. G. Duckett, J. G. Culotti, R. K. Herman, P. N. Meneley, and R. L. Russell (1981) An acetylcholinesterase-deficient mutant of the nematode Caenorhabditis elegans. Genetics 97: 261-279.

Lewis, J. A., C. H. Wu, J. H. Levine, and H. Berg (1980a) Levamisoleresistant mutants of the nematode Caenorhabditis elegans appear to lack pharmacological acetylcholine receptors. Neuroscience 5: 967-989

Lewis, J. A., C. H. Wu, H. Berg, and J. H. Levine (1980b) The genetics of levamisole resistance in the nematode Caenorhabditis elegans. Genetics 95: 905-928.

Rand, J. B., and C. D. Johnson (1981) A single-vial biphasic liquid extraction assay for choline acctyltransfcrasc using $\left[{ }^{3} \mathrm{H}\right]$-choline. Anal. Biochem. 116 . 361-371.

Rand, J. B., and R. L. Russell (1984) Choline acetyltransferase-deficient mulanls of the nermatude Caenorhaboditis elegans. Genetics 106: $227-$ 248 
Rand, J. B., and R. L. Russell (1985) Properties and partial purification of choline acetyltransferase from the nematode Caenorhabditis elegans. J. Neurochem. 44: 189-200.

Rossier, J. (1976) Purification of rat brain choline acetyltransferase. J. Neurochem. 26: 543-548.

Russell, R. L., C. D. Johnson, J. Rand, S. Scherer, and M. Zwass (1977) Mutants of acetylcholine metabolism in the nematode Caenorhabditis elegans. J. Supramol. Struct. 8: 359-371.

Stretton, A. O. W., R. M. Fishpool, E. Southgate, J. E. Donmoyer, J. P. Walrond, and I. S. Kass (1978) Structure and physiological activity of the motorneurons of the nematode Ascaris. Proc. Natl. Acad. Sci. U. S. A. 75: 3493-3497.

Walrond, J. P., and A. O. W. Stretton (1985) Reciprocal inhibition in the motor nervous system of the nematode Ascaris: Direct control of ventral inhibitory motoneurons by dorsal excitatory motoneurons. J. Neurosci. 5: 9-15.

Walrond, J. P., I. S. Kass, A. O. W. Stretton, and J. E. Donmoyer (1985) Identification of excitatory and inhibitory motoneurons in the nematode Ascaris by electrophysiological techniques. J. Neurosci. 5: 1-8.

White, J. G., E. Southgate, J. N. Thomson, and S. Brenner (1976) The structure of the ventral nerve cord of Caenorhabditis elegans. Philos. Trans. R. Soc. Lond. (Biol.) 275: 298-327. 